\title{
Occupational stress and gender: a cross-cultural study
}

\author{
Karen Miller*,†, ${ }^{*}$ Mike Greyling ${ }^{1}$, Cary Cooper ${ }^{2}$, Luo Lu ${ }^{3}$, Kate Sparks ${ }^{2}$ \\ and Paul E. Spector ${ }^{4}$ \\ ${ }^{1}$ University of the Witwatersand, South Africa \\ ${ }^{2}$ University of Manchester Institute of Science and Technology, U.K. \\ ${ }^{3}$ Graduate Institute of Behavioural Sciences, Taiwan \\ ${ }^{4}$ University of South Florida, U.S.
}

\begin{abstract}
Summary
The aim of this study was to examine the interaction of gender and culture in managers' experiences of work stress. Data were collected on sources of occupational stress (stressors), coping and consequences of occupational stress (strains) from male and female managers from four countries - South Africa, the United Kingdom, United States of America and Taiwan. Few significant results were found for the interaction between country and gender on any of the measures. When the sample as a whole was examined, however, there were also virtually no differences in sources of work stress, but there were differences in the consequences of work stress for male and female managers. The implications of finding a lack of differences in sources of work stress for males and females combined with finding differences in strains for male and female managers are discussed. Copyright (C) 2000 John Wiley \& Sons, Ltd.
\end{abstract}

\section{Key Words}

stress; work stress; gender and stress

The entry of women into managerial and professional organisational roles over the last three to four decades has been accompanied by a substantial amount of research which has examined the impact of this change on the organisation, the woman and her family. ${ }^{1}$ In particular, the issue of women's work-related stress has received attention, beginning in the 1980s when the effects of the increase in the numbers of women in nontraditional/senior organisational levels in the United Kingdom (UK) and the United States of America (USA) began to be felt. However, the

* Correspondence to: Karen Miller, Department of Psychology, University of the Witwatersrand, Private Bag 3, WITS 2050, South Africa. Fax: 27117162476. $\dagger$ E-mail: 018karen@muse.arts.wits.ac.za results of the research in this area tended to be inconclusive. For example, Jick and $\mathrm{Mitz}^{2}$ reviewed the empirical evidence for sex differences in work stress from 19 studies and found that women tend to report higher rates of psychological distress than men, but that men are more prone to more severe physical illness. Further, a review conducted by Nelson and Quick $^{3}$ indicated that employed women experience greater stress than both non-employed women and men because of several unique stressors faced by employed women. Baruch, Biener and Barnett ${ }^{4}$ on the other hand, found that non-employed women experience greater stress than employed women, while Martocchio and O'Leary ${ }^{5}$ who undertook a meta-analysis of 15 studies that examined sex differences in occupational stress, found no differences in experienced and perceived work stress. On the basis of their findings, Martocchio and O'Leary ${ }^{5}$ 


\section{K. Miller et al.}

argued that 'this analysis does not represent irrefutable evidence that there are no differences in occupational stress. The burden of proof does, however, now lie with those researchers who suggest that sex differences exist. Future researchers should not spend time debating the nature of the sex occupational stress relationship when the existence of the relationship is now the salient issue' ( p. 500). Subsequent to this assertion, there seem to have been fewer research studies aimed specifically at comparing men and women's work-related stress.

The results of the studies that have been done more recently (e.g. Guppy and $\mathrm{Rick}^{6}$ and Narayanan, Menon and Spector ${ }^{7}$ ) have been as contradictory as the studies of the 1980s. Moreover, the emphasis in the literature on gender and stress seems to have shifted towards the development of theoretical perspectives relating to women and stress (e.g. Greenglass ${ }^{8}$; Matuszek, Nelson and Quick $^{9}$ ). This may be because the entry of women into 'non traditional'/senior organisational positions in developed countries such as the USA and the UK (from where much of this type of research has traditionally originated) became less topical. Women's entry into the above mentioned positions in these countries, while still not equal to that of men, has become a fait accompli, with non-discrimination against women in a country like America being enforced through equal opportunity legislation.

In developing countries, however, the entry of women into managerial or senior managerial positions has been slower, with women only now beginning to take up roles in these positions in significant numbers. In South Africa, for example, gender discrimination in the workplace has been outlawed only recently with the passing of the Labour Relations Act in 1995 and the Employment Equity Act last year. Moreover, even with this legislation in place, issues related to racial discrimination in the workplace far outweigh gender discrimination in South Africa (for obvious reasons, given South Africa's recent, apartheid history). Similarly, in Taiwan there is anti-discrimination legislation, but it is of fairly recent origin; and while labor laws exist which provide for such things as maternity leave, employers do not always grant it. Women have also complained of being forced to quit jobs because of age or child-bearing restrictions, and restrictive quotas reputedly exist within certain occupations. ${ }^{10}$ Women often receive less frequent promotions and lower salaries than their male counterparts. ${ }^{10}$

Given this context, it seems likely that gender differences in the work environment in developing countries may still be an issue. Thus, the present study, which includes a sample of men and women managers from four different countries of differing levels of development, namely the UK, USA, Taiwan and South Africa provides a unique opportunity to revisit some of the issues in gender and occupational stress from a cross cultural perspective.

\section{The research questions}

Based on the above discussion, a number of research questions for this paper were developed. The first set of questions are the same as many of those posed, but not satisfactorily answered in the research of the 1980s. These are:

1. Do men and women differ in the sources of work stress (stressors) they experience?

2. Do men and women differ in the mechanisms they use to cope with work stress?

3. Do men and women differ in their experiences of the consequences of work stress (strains)?

Further questions, taking the cross-cultural nature of the study into account were then developed as follows:

1. Is there an interaction between country and gender in managers' experiences of work stress (stressors)?

2. Is there an interaction between country and gender in the mechanisms managers use to cope with stress?

3. Is there an interaction between country and gender in managers' experiences of the consequences of work stress (strains)?

\section{Method}

In order to answer the above questions, data from the Collaborative International Study of Managerial Stress (CISMS) from four countries was obtained. The CISMS project was established in 
Table I. Biographical details of the sample. $N=822$.

\begin{tabular}{|c|c|c|c|c|c|c|c|c|}
\hline \multirow[t]{2}{*}{ Country } & \multicolumn{2}{|c|}{ Males } & \multicolumn{2}{|c|}{ Females } & \multirow[t]{2}{*}{ Mean age } & \multirow{2}{*}{$\begin{array}{l}\text { Mean } \\
\text { tenure }\end{array}$} & \multirow[t]{2}{*}{$\%$ college } & \multirow[t]{2}{*}{$\%$ married } \\
\hline & $N$ & $\%$ & $N$ & $\%$ & & & & \\
\hline Taiwan & 191 & 40.6 & 151 & 43.0 & 37.9 & 10.2 & 100 & 74 \\
\hline UK & 117 & 24.8 & 106 & 30.2 & 43.7 & 15.5 & 64 & 83 \\
\hline SA & 98 & 20.8 & 42 & 12.0 & 36.2 & 8.1 & 98 & 71 \\
\hline USA & 65 & 13.8 & 52 & 14.8 & 43.9 & 9.5 & 89 & 71 \\
\hline Total & 471 & 100 & 351 & 100 & & & & \\
\hline
\end{tabular}

1996 as an effort among researchers in different countries to conduct cross-national research on stress. As mentioned above, data from four countries in the CISMS study were used for the present research, namely, Taiwan, the UK, South Africa and the USA. The CISMS study includes 24 countries, but not all the countries' data were available at the time of doing this study. The reasons for choosing Taiwan, South Africa, the USA and the UK was to get data from developed countries (the USA and UK), a developing country (Taiwan) and an underdeveloped country (South Africa). More details of the sample are presented in Table I.

\section{Sample}

The sample comprised 822 managers from four countries. Subjects for the study were recruited by the individual researchers in each country. The researchers were asked to try and obtain representative samples of managers for each country and not to focus only on one organisation. However, other than this request, the recruitment of the subjects was left entirely to the discretion of each researcher. As a result, the sample sizes varied quite widely. The biographical details of the sample for each country are presented in Table I. What is important here is that, although the numbers of male and female managers from each country are not equal, there are sufficient numbers of males and females in each sub-sample to allow for meaningful statistical analyses. The mean age ranged from 36.2 (South Africa) to 43.9 (the US) and the mean tenure ranged from 8.1 (South Africa) to 15.5 (the UK). The majority of participants from all the countries had attended some college, with the lowest proportion (64 per cent) from the UK and the highest from Taiwan (100 per cent). More than two thirds of the sample in each country were married.

\section{Measures}

The samples from all the 22 countries in the original CISMS study were administered the Occupational Stress Indicator-2 (OSI-2), a 90 item scale that assesses job strains, sources of stress, personality and coping; ${ }^{11}$ the Work Locus of Control Scale; ${ }^{12}$ the Hofstede ${ }^{13}$ Values Survey Module 1994 Questionnaire and 22 additional questions, including demographics. Only the OSI-2 was used for the purposes of the present paper and therefore it is the only scale that will be discussed further.

The OSI-2 is a 90 item short form of the OSI. ${ }^{14}$ The Sources of Work Pressure (work stressors), Coping, Physical Strain and Mental Strain measures were relevant for the present study. Details of the sub-scales are given in Table II, including the estimated reliabilities for the current sample. Using the cut-off of $0.70^{15}$ as an indication of minimal acceptable reliability, three subscales did not meet this criterion. Therefore, only the composite scales for these variables were used in the current study.

\section{Results}

The data was subjected to the statistical analysis techniques of ANOVA and the two independent sample $t$-test. First, $t$-tests were conducted to assess the differences between males and females on the above variables for the sample as a whole. Then a two way ANOVA was conducted to assess the interaction between country and gender on the variables under consideration.

The results of the $t$-tests for the sample as a whole are presented in Table III. As can be seen from this table, significant differences emerged on four of the variables. The first is stress from organisational climate, a sub-scale of the sources 


\section{K. Miller et al.}

Table II. A description of the OSI-2, including reliabilities estimated from the current sample. $N=822$.

\begin{tabular}{lcll}
\hline Variable & Number of items & Alpha & Higher score indicates: \\
\hline Sources of work stress & 40 & 0.946 & Higher stress \\
Workload & 6 & 0.820 & \\
Relationships & 8 & 0.887 & \\
Home/work balance & 6 & 0.819 & \\
Recognition & 4 & 0.736 & \\
Organisational climate & 4 & 0.843 & \\
Managerial role & 4 & 0.586 & \\
Personal responsibility & 4 & 0.802 & \\
Hassles at work & 4 & 0.647 & Greater use of coping strategies \\
Coping strategies & 10 & 0.783 & \\
Control & 6 & 0.776 & Better mental well being \\
Support & 4 & 0.514 & \\
Mental well-being & 12 & 0.652 & Better physical well-being \\
Contentment & 5 & 0.800 & \\
Peace of mind & 3 & 0.555 & \\
Physical well-being & 6 & 0.842 & \\
Calmness & 3 & 0.903 & \\
Energy & 3 & 0.696 & \\
\hline
\end{tabular}

Table III. Results of the $t$-tests for the whole sample.

\begin{tabular}{lcccr}
\hline Variable & \multicolumn{2}{c}{ Means } & $d f$ & \multirow{2}{*}{$t$} \\
\cline { 2 - 3 } & Males & Females & \\
\hline Sources of pressure & & & & \\
$\quad$ Workload & 21.822 & 22.322 & 805 & -1.1431 \\
Relationships & 28.869 & 29.724 & 803 & -1.5316 \\
$\quad$ Home/work balance & 18.558 & 18.539 & 790 & 0.0381 \\
Managerial role & 13.167 & 13.158 & 807 & 0.0363 \\
Personal responsibility & 14.575 & 15.117 & 802 & -1.8293 \\
Hassles & 13.497 & 13.886 & 807 & -1.5416 \\
Recognition & 14.231 & 13.939 & 804 & 0.9370 \\
Organisational climate & 14.755 & 15.405 & 807 & $2.6072^{* *}$ \\
Coping strategies & 40.981 & 42.170 & 810 & $-2.8551^{* *}$ \\
Mental well-being & 31.144 & 29.578 & 807 & $3.1119^{* *}$ \\
Physical well-being & 26.201 & 25.104 & 812 & $2.6546^{* *}$ \\
\hline
\end{tabular}

$* p<0.05$.

$* * p<0.01$

$* * * p<0.001$.

of job pressure measure. For this sub-scale, males scored higher than females. There were also significant differences on both the total coping score and the coping using social support scale, with women being higher on coping using social support and men higher on total coping. Finally, males scored significantly higher on both physical and mental well-being than women, indicating better well-being among men.

As far as the interaction of gender and country on differences in work stress are concerned, significant results were found for four variables, namely, stress from managerial role, coping strategies, mental well-being and physical wellbeing. A summary of these results is given in Table IV.

In order to examine these interactions more carefully, post hoc analyses were conducted on those variables that showed significant interactions. T-tests by country were conducted for each of these variables, the results of which are presented in Table V. Straight $t$-tests were used 
Table IV. Summary of the results for the interaction between gender and country.

\begin{tabular}{lcc}
\hline Variable & $d f$ & $F$ \\
\hline Sources of pressure & & \\
$\quad$ Workload & 3,799 & 0.38 \\
Relationships & 3,797 & 1.27 \\
Home/work balance & 3,784 & 0.71 \\
Managerial role & 3,801 & $2.88^{*}$ \\
Personal responsibility & 3,796 & 0.20 \\
Hassles & 3,801 & 0.66 \\
Recognition & 3,798 & 1.03 \\
Organisational climate & 3,801 & 1.26 \\
Coping strategies & 3,804 & $2.62^{*}$ \\
Mental well-being & 3,801 & $3.43^{*}$ \\
Physical well-being & 3,806 & $2.74^{*}$ \\
\hline
\end{tabular}

rather than the usual least significant difference approach to post hoc analyses for two reasons. First, the research question implies that the gender differences across the countries were of specific interest. Thus, only four comparisons were examined, viz. males and females were compared for each country. Second, the $t$-tests were performed using a variance estimate based only on the country being compared rather than the mean square error as is usually the case for post hoc comparisons. This allowed the procedure to be more robust in the face of possible departures from the variance homogeneity assumption.

From Table V, it is clear that as far as mental well-being is concerned, American males scored highest. South African males, British males and American females were all fairly similar, followed fairly closely by Taiwanese females and then males, with British and South African females obtaining the lowest scores on this variable. With regard to physical well-being, American males again scored highest followed by British males and American females. British females came next, followed by Taiwanese males, South African males and Taiwanese females, with South African females again scoring lowest on this scale. With regard to coping, Taiwanese females scored highest, followed by Taiwanese males and American and British females. In this case, South African females, males and American males respectively were all fairly similar, while UK males obtained the lowest scores. Finally, results relating to the one stressor that emerged as significant in the ANOVA analyses - stress from managerial role - did not show significant differences for the individual country $t$-tests. The large sample size coupled with a relatively small $f$ statistic indicates a small and probably unimportant effect.

Table V. Results of the $t$-tests by country.

\begin{tabular}{|c|c|c|c|c|}
\hline \multirow[t]{2}{*}{ Country } & \multicolumn{2}{|c|}{ Means } & \multirow[t]{2}{*}{$d f$} & \multirow[t]{2}{*}{$t$} \\
\hline & Males & Females & & \\
\hline \multicolumn{5}{|c|}{ Mental well-being } \\
\hline Taiwan & 10.367 & 10.757 & 334 & -1.203 \\
\hline UK & 10.800 & 9.962 & 219 & $2.0712^{*}$ \\
\hline SA & 10.938 & 9.167 & 137 & $3.0926^{*}$ \\
\hline USA & 11.585 & 10.706 & 114 & 1.5388 \\
\hline \multicolumn{5}{|c|}{ Physical well-being } \\
\hline Taiwan & 25.300 & 24.851 & 336 & 0.7458 \\
\hline UK & 27.374 & 25.972 & 219 & 1.9258 \\
\hline SA & 25.196 & 21.262 & 137 & $3.3856 * * *$ \\
\hline USA & 28.262 & 27.196 & 114 & 0.9527 \\
\hline \multicolumn{5}{|c|}{ Pressure from managerial role } \\
\hline Taiwan & 14.368 & 15.203 & 331 & -2.4897 \\
\hline UK & 11.843 & 11.245 & 219 & 1.3572 \\
\hline SA & 12.711 & 12.143 & 137 & 0.8001 \\
\hline USA & 12.677 & 12.235 & 114 & 0.7730 \\
\hline \multicolumn{5}{|c|}{ Coping strategies } \\
\hline Taiwan & 43.356 & 43.818 & 334 & -0.8103 \\
\hline UK & 38.287 & 40.783 & 219 & $-4.1916^{* * *}$ \\
\hline SA & 39.948 & 39.452 & 137 & 0.3557 \\
\hline USA & 10.415 & 42.510 & 114 & -1.9049 \\
\hline
\end{tabular}




\section{Discussion}

As far as the first set of research questions are concerned, the findings indicate that for the whole sample (i.e. all four countries) there were virtually no differences in the stressors experienced by men and women (with the sole exception of stress from organisational climate). There were differences, however, in the strains experienced by men and women, specifically mental well-being and physical well-being, with men exhibiting better mental and physical wellbeing than women. This supports the conclusion of Matuszek, Nelson and Quick ${ }^{9}$ that men and women operating at roughly the same level within organisations generally experience the same stressors, but experience different levels of distress as a result. These findings must, however, be viewed with caution as they come from the combining of four data sets, each of which differ significantly on the variables under consideration.

This, then, leads to the second set of research questions, which dealt specifically with the interaction between country and gender on difference in stressors, coping and strain. For these analyses, the only significant difference in stressors that emerged was managerial role as a source of pressure. Significant differences on coping emerged again in this set of analyses, as well as on mental and physical well-being. Unfortunately, the ANOVA procedure used to established these differences does not indicate where the actual differences between the countries and genders lie, and therefore $t$-tests by country were conducted for each of the variables mentioned above. It is recognized that this is neither a definitive nor ideal method of establishing the precise nature of the difference, but it does provide an indication of whether patterns are emerging which can give some insight into the findings.

The $t$-test results revealed the following:

- For both the UK and South Africa differences emerged between men and women on mental well-being.

- South Africa was the only country where a significant difference between males and females emerged with regard to physical well-being.
- The UK was the only country where a significant difference between males and females emerged with regard to coping strategies.

There are two issues that need to be discussed as far as the findings are concerned. The first issue is whether any pattern emerged with regard to countries and stress and how such a pattern, if any, relates to the assumptions underlying this research. The second issue is the nature of the variables that emerged as significantly different, regardless of country. As far as the first issue is concerned, it appears as if not much of a pattern seems to be emerging at all. This goes against the underlying assumption of this research - that developing countries are more likely than developed countries to exhibit gender differences due to the relatively recent entry of women into managerial positions in these countries and due to a relatively lower emphasis on women's rights in developing countries. The lack of significant differences in the USA between men and women on all the variables does, however, lend partial support to the initial argument that prompted this research. This must, however, be viewed with caution, given the particularly small American sample size. It is also possible that the relatively few countries included in the study could account for the lack of significant findings with regard to the interaction between country and gender on the stressors. Future research could perhaps include a larger number of developed, developing and underdeveloped countries to establish any differences more clearly.

It appears that what is perhaps more relevant is what was not found in the current study. Discussing non-significant findings is somewhat unusual, if not generally frowned upon in research papers; however, in the context of the debates in the literature on occupational stress and gender it seems appropriate to explore this issue briefly. The relatively large sample size also gives more weight to the meaning of non-significant findings.* As mentioned at the start of this paper, Martocchio and O'Leary $^{5}$ stated that no differences in experienced stress between men and women in a

* Large samples imply increased statistical power and hence lower the likelihood of a type II error. In essence, the higher power implies that if a mean difference was large enough to be of import, then the statistical analysis should be able to find it. 
work setting had been established, while Jick and Mitz $^{2}$ did find gender differences in this area. Subsequent research ${ }^{6,7}$ has tended to be equally contradictory. The aim of this study was to re-visit the issue from a cross-cultural perspective in an attempt to provide greater clarification. The findings of the current study support the view of Martocchio and O'Leary. ${ }^{5}$ The only differences to have emerged consistently from the analyses in the current study were on the measures of strain (distress) rather than the work stressors. At this point, it needs to be acknowledged that this could be a function of women being more likely to report feelings of physical and mental ill-health than men $^{8}$ or perhaps being more aware of symptoms of mental or physical health than men. This is a difficult issue to overcome, since even seemingly more objective measures than self reporting of symptoms, such as visits to doctors and sick leave, may be affected by this fundamental bias, if it exists.

An alternative explanation for the lack of significant results regarding work stress and coping, together with the finding of significant differences in some of the strains measures, may be that the greater distress experienced by women has nothing to do with their work role/s. It is often assumed that the strains experienced by working women are a consequence of their work-related stress or at the very least work/home overload and conflict. This may not be the case. Indeed, Greenglass $^{8}$ argues that because stress research has focused primarily on men, the job has been identified as the primary stressor, having negative psychological effects. The home, on the other hand, has been viewed as a sanctuary from workrelated stress. She goes on to say that 'such a perspective reflects ... the assumption that, for women, the roles associated with home, wife, mother, homemaker are somewhat free from undue stress' (p. 123). The greater psychological and physical ill-health reported by women in this study could thus be attributed to greater stress from the external environment, rather than from the workplace. Even if this argument is accepted as plausible, however, this does not mean that the greater distress experienced by women as opposed to male managers should not be a workplace concern. Taking an open systems perspective, whereby organisations influence and are influenced by their external environments, ignoring the impact of non-work related stress on employees could jeopardize workplace stress reduction efforts. To address workplace stress from a holistic perspective therefore, it may be necessary to address both the work and non-work stress experienced by women managers in particular, and future research efforts could perhaps be directed towards examining the interaction of work and non-work stressors in determining strain.

\section{Conclusion}

The aim of this study was to exploit the opportunities provided by the CISMS project to examine gender differences in work stress from a cross-cultural perspective. Like many previous studies in this area, the present research failed to support the notion that there are gender differences in work stress and only limited support was found for the notion of an interaction between gender and country on work stress. Those differences that did emerge in the various analyses conducted, related primarily to differences in strains (distress). A number of possible explanations for the findings were provided. These ranged from attributing the lack of significant findings to the limited number of countries in the study, to accepting that the lack of significant findings may indeed be reflecting that gender issues in work stress is a non-issue, at least in the occupational stress variables measured here. Finally, the implications of the findings regarding the differences in the strain measures were examined, with the main one being the importance of examining the role of extra-organisational stressors on female managers' distress.

\section{References}

1. Barling J, Sorensen D. Work and family: in search of a relevant research agenda. In Creating Tomorrow's Organizations. A Handbook for Future Research in Organizational Behaviour, Cooper CL, Jackson SE (eds). John Wiley and Sons: Chichester, 1997; 157-170.

2. Jick TD, Mitz LF. Sex differences in work stress. Acad. Management Rev. 1985; 10(3): 408-420.

3. Nelson DL, Quick JC. Professional women: are distress and disease inevitable? Acad. Management Rev. 1985; 10(2): 206-218

4. Baruch GK, Biener L, Barnett RC. Women and gender in research on work and family stress. Am. Psychol. 1987; 42: 130-136. 


\section{K. Miller et al.}

5. Martocchio JJ, O’Leary AM. Sex differences in occupational stress: a meta-analytic review. J. Appl. Psychol. 1989; 74(3): 495-501.

6. Guppy A, Rick J. The influence of gender and grade on perceived work stress and job satisfaction in white-collar employees. Work and Stress 1996; 10(2): 154-164.

7. Narayanan L, Menon S, Spector PE. Stress in the workplace: a comparison of gender and occupations. J. Org. Behav. 1999; 20: 63-73.

8. Greenglass ER. Gender, work stress and coping: theoretical implications. J. Soc. Behav. Personal. 1995; 10(6): 121-134.

9. Matuszek PAC, Nelson DL, Quick JC. Gender differences in distress: are we asking all the right questions? J. Soc. Behav. Personal. 1995; 10(6): 99-120.
10. U.S. Department of State. Taiwan Human Rights Practices. 1994.

11. Cooper CL, Williams S. Occupational Stress Indicator Version 2.0. NFER-Nelson: Windsor, 1996.

12. Spector PE. Development of the work locus of control scale. J. Occupat. Psychol. 1988; 61: 335-340.

13. Hofstede G. Values Survey Module 1994 Manual. Institute for Research on Intercultural Co-operation: Maastrich, 1994.

14. Cooper CL, Sloan SJ, Williams S. Occupational Stress Indicator Management Guide. NFER-Nelson: Windsor, 1988.

15. Nunnally JC. Psychometric Theory (2nd ed). McGraw Hill: New York, 1978. 